\title{
Conversaciones en centros residenciales de personas mayores durante la covid-19: impacto en las profesionales de los cuidados
}

\section{Raquel Lázaro}

Directora de Cultura y Liderazgo, Matia Fundazioa

\section{Sandra Pinzón}

Profesora, Escuela Andaluza de Salud Pública

\section{Pura Díaz-Veiga}

Investigadora, Matia Instituto

pura.diaz-veiga@matiafundazioa.eus

\section{Penelope Castejón Villarejo}

Investigadora, Matia Instituto

\section{Maider Azurmendi}

Responsable de Cooperación, Matia Fundazioa Investigadora, Matia Instituto

\section{Alberto Uriarte \\ Responsable del Servicio de Valoración, Matia Fundazioa}

Ikerketak, COVID-19 krisialdian, Pertsona Ardatz duen Arreta ikuspegia aplikatzen duten adinekoen egoitzetako 146 profesionalen esperientzia aztertzen du. Krisiak mundu-mailako ondorioak izan zituen orokorrean eta pertsona ardatz duten arretaeremuetako lotura-harremanetan aldaketa bortitzak eragin zituen. Hauek berreskuratzen dituztenak, parte izatearen sentimendua, xedea, lantaldea, konfiantza eta jarrera positiboa dira. Informazioa, parte-hartzea, aitortza eta topaguneak izatea ongizatea sustatzeko estrategiatzat jotzen dira, ez ordea osasun larrialdietan soilik, baita pertsona ardatz duten testuinguruetan ekintza egonkor gisara ere.

\section{GAKO-HITZAK:}

Pertsona ardatz duen arreta, adinekoak, COVID-19, egoitzak, eguneko zentroak.
Este artículo analiza la experiencia durante la crisis de la covid-19 de 146 profesionales que aplican el enfoque de atención centrada en la persona en residencias de personas mayores. Según los testimonios, la crisis tuvo efectos globales y provocó un cambio brusco en los vínculos relacionales sobre los que se sustenta la atención centrada en las personas. La certeza que recompone estos vínculos se encuentra en la pertenencia, el propósito, el equipo, la confianza y una actitud positiva. La información, la participación, el reconocimiento y los lugares de encuentro se identifican como estrategias promotoras de bienestar, no solo en situaciones de emergencia sanitaria sino también como acciones estables en contextos de cuidados centrados en las personas.

\section{PALABRAS ClaVe:}

Atención centrada en la persona, personas mayores, covid-19, residencias, centros de día. 


\section{Introducción}

En las personas mayores que viven en centros residenciales se ha evidenciado una especial vulnerabilidad frente a la enfermedad producida por el virus SARS-CoV-2 y un peor pronóstico asociado a sus condiciones de salud y a las condiciones del propio entorno (Roqué y Coll-Planas, 2020; Deusdad, 2020). Las medidas restrictivas que se han puesto en marcha para evitar la propagación del virus en las residencias han derivado en la interrupción de las rutinas diarias, en la reducción de la interacción social, en la limitación del acceso a las redes de apoyo y en la suspensión de las actividades agradables y estimulantes que se realizaban a nivel individual o grupal en estos centros (McMichael, 2020; Armitage y Nellums, 2020). El efecto de estas medidas ha sido especialmente negativo para las personas con demencia, que han mostrado su desorientación, confusión, exacerbación de los trastornos de conducta y el incremento de síntomas neuropsiquiátricos como los delirios, las alucinaciones y la agitación, ente otros (Deusdad, 2020).

A su vez, las trabajadoras responsables del cuidado en los centros residenciales se han enfrentado a desafíos extraordinarios en el día a día. Han asumido una sobrecarga en el cuidado que tiene un impacto potencial sobre su propio bienestar y el de las personas que cuidan. La situación en muchos momentos se ha vivido desde la amenaza y el miedo ante la incertidumbre, factores que afectan a su capacidad de ofrecer una atención compasiva y centrada en la persona (Houghton et al., 2020; Stacey, 2020).

Estudios recientes muestran la falta de modelos de intervención que aporten elementos clave para prevenir, minimizar o revertir estos efectos, tanto en personas mayores como en los equipos profesionales que prestan cuidados (Bedford et al., 2020; Kunzler et al., 2020; Roqué y Coll-Planas, 2020; Stacey, 2020). Y es en este contexto en el que se propone este estudio que busca comprender la experiencia vivida por profesionales de una organización que aplica el enfoque de la Atención Centrada en la Persona (ACP), durante la primera oleada de la pandemia generada por la covid-19, para definir las estrategias de intervención en la mejora de la gestión emocional y del bienestar de las personas mayores y profesionales que les prestan apoyo y cuidados.

\section{Método}

Se llevó a cabo un estudio cualitativo a través de entrevistas individuales y grupales con profesionales de una organización privada sin ánimo de lucro, con más de 130 años de experiencia en la prestación de servicios a personas mayores en Gipuzkoa. En la última década, esta organización ha implantado el enfoque de ACP en sus centros y servicios (Lupianez et al., 2015; McCormack y McCance, 2017).
El estudio se llevó a cabo durante el estado de alarma provocado por la covid-19. La información fue recogida del 15 de abril al 30 de julio de 2020 . Participaron en el estudio 146 profesionales sociosanitarios (auxiliares, enfermeras, médicas, trabajadoras sociales, psicólogas, fisioterapeutas, directoras de residencias, personal de soporte y representantes sindicales). En todos los casos, la participación fue voluntaria y con el deseo expreso de compartir la experiencia vivida.

El tamaño de la muestra estuvo condicionado por la saturación de los temas emergentes durante la realización de las entrevistas. Aun así, las conversaciones se extendieron a todas aquellas personas que manifestaron su deseo de participar en el proceso, propiciando a través de estas conversaciones un espacio en el que integrar la experiencia, encontrar recursos personales y profesionales y generar aprendizajes. Las entrevistas fueron realizadas por videoconferencia, teléfono o de forma presencial, grabadas y transcritas, previo consentimiento de las personas entrevistadas, a quienes se garantizó el anonimato y la confidencialidad de la información recogida.

Se utilizó la técnica de análisis del discurso para explorar los hechos significativos para las personas entrevistadas y cómo éstos contribuyen a la constitución de sus propias realidades sociales. Este tipo de análisis permite comprender las contradicciones que surgen en contextos de confusión y alto grado de incertidumbre y riesgo, como el que originó la covid-19. El análisis de las entrevistas se apoyó en NVivo 12.

\section{Resultados}

La codificación abierta de los discursos iniciales recogidos generó 86 categorías que se agruparon en ocho dimensiones que contribuyen a comprender la experiencia vivida durante la primera oleada de la pandemia (Ilustración 1). Se describen a continuación cada una de ellas.

\subsection{Miedo}

El miedo al contagio se genera y crece cuando se adquiere conciencia sobre la gravedad de la enfermedad y la necesidad de prevenir y controlar la propagación del virus en los centros. Y se normaliza cuando las medidas de protección y prevención se incorporan en la práctica profesional. El lavado de manos, el uso de la mascarilla y los demás equipos de protección individual (EPI) se incorporan al día a día y generan una cierta tranquilidad.

[...] es miedo, no sabes a qué, a lo desconocido, yo he vivido con bichos, he estudiado sobre esto, y los bichos no me asustaban, este sí, no lo conozco, el no saber, y tanta información contradictoria ya desde China, cómo evoluciona, 


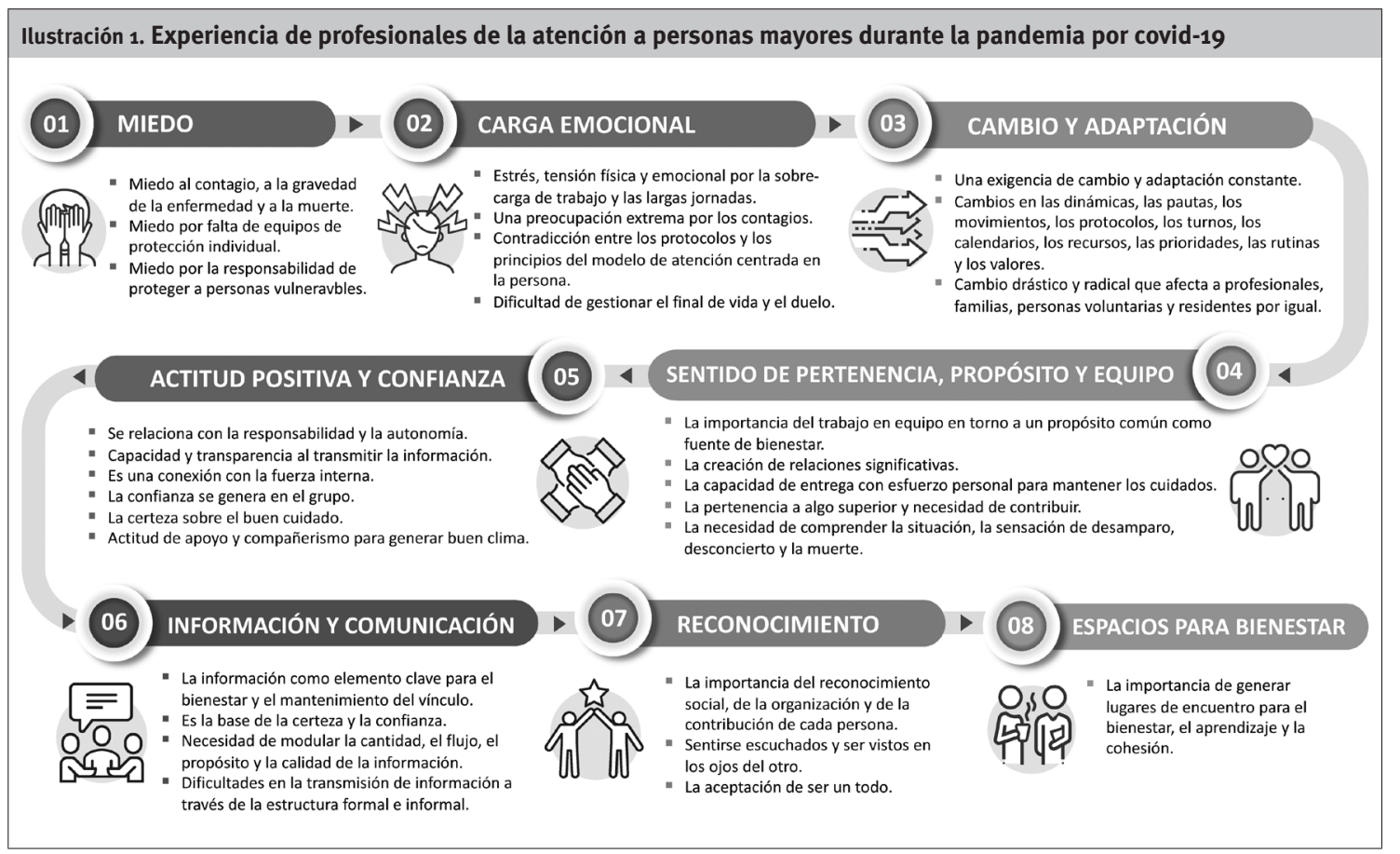

Fuente: Matia Fundazioa, con licencia Freepick.

de una manera, pero luego se hacen cosas que no, mi cabeza... va a su ritmo, miedo por esto, miedo por mi casa y miedo por mí.

Yo he vivido al principio esta covid con mucho miedo, con muchísimo miedo, el miedo era visceral, desde la tripa me salía el miedo, no sé si calificarlo de histeria, y no creo que soy intolerante, trato de ser empática, pero sí con mucho, con mucho miedo, con mucho temor por mí, por mi hija, que nos tenemos la una a la otra, por las dos, estamos las dos solas, y después por donde estoy trabajando, estamos trabajando con seres humanos, no estaba en una fábrica donde se cerraba y yo me quedaba tranquilamente en mi casa. También era prevenir y dar el mayor confort a la gente con la que estamos trabajando. He comenzado limpiando todo lo que se podía, las sillas todos los días para evitar que hubiese contagio en la manipulación, he hecho todo lo que estaba a mi alcance, sin tener conocimiento de nada, porque esto ha sido algo nuevo para todos, hemos ido improvisando a medida que ha ido avanzando la situación. Yo creo que desde el primer trabajador hasta el último hemos ido recorriendo este camino, a trancas y barrancas y hoy era una cosa y a los dos minutos era otra cosa.

La falta de EPI protectores de la enfermedad ha producido malestar, información contradictoria y cambiante en referencia a estos, corrillos de interpretación, “chascarrillos", malos entendidos, inseguridad, miedo e indignación.

[...] primero qué mascarillas tuvimos, primero las blancas de tela, y ya se empezó a decir que la
FPP2 era la adecuada, y aquí aún con las de tela, se generaban corrillos, pues cuando salimos a fumar o a tomar el café, ahí si se hablaba, y se generó malestar de que no teníamos el material adecuado que se necesitaba. Cuando se empezó a traer de las buenas nos tranquilizamos.

El miedo a estar cerca de las personas residentes se ha manifestado al mismo tiempo que la responsabilidad de cuidar. Al final "tienes que tranquilizarte para tranquilizar al otro". Hacer todo lo posible para minimizar el riesgo de contagio supone un reto cada día y, cuando se consigue, un sentimiento de orgullo y alegría.

Ahora ya nos vamos lavando un poco más las manos y siento más seguridad [...]. Yo siempre digo, si los residentes están bien, nosotros también estamos bien. 0 sea, que eso te da un poco de seguridad también en ti mismo y al estar tú bien... A veces siento más miedo cuando estoy en la calle que de estar dentro de la residencia.

El miedo a hacer algo mal y contagiarse tiene estrecha relación con la información necesaria para actuar con seguridad. Asimismo, la falta de EPI incrementa la percepción de vulnerabilidad y el miedo al contagio.

Luego está el tema de los equipos de protección, el tema de las mascarillas, de la sensación de vulnerabilidad, que la seguimos teniendo, no sabemos si tenemos mascarillas, si no tenemos mascarillas, de repente sale un protocolo que los de más de sesenta tenemos que usar un tipo de mascarillas, son súper incómodas, para comunicarte con el paciente es súper incómodo, 
no nos reconocen la cara, y no ayuda al tipo de paciente.

Para superar los miedos, los equipos se han volcado en su trabajo pensando solo en aportar lo mejor posible, con una sensación de cohesión y con el propósito de proteger y cuidar.

Yo creo que todo el mundo nos hemos volcado, hemos dejado nuestros miedos y hemos pensado en aportar y hacer lo mejor posible. Y en nuestro caso, quizá somos un equipo que estamos muy unidos, que estamos todos a una y bueno, de lo malo, malo, hemos vivido aquí...

Las rutinas de trabajo se han visto alteradas por el miedo al contagio, generando divisiones entre los equipos de atención directa en planta y los equipos interdisciplinares. Esto en ocasiones ha producido una vivencia de abandono y soledad en el personal.

La gente que ha trabajado en planta y no en unidad de covid, que han estado más acompañadas, si han sentido ese desamparo de la gente de la zona cero, de la inter; no es que tengan que venir a hacer tu trabajo, es que vengan a preguntarte qué tal vais, cómo estáis, que esto la monitora si lo ha dado, y siempre disponible, pero otra gente no ha venido ni a preguntar qué tal estamos.

El miedo, el enfado y la tristeza se perciben mal en los equipos. Muchas veces la susceptibilidad ha sustituido a estas otras emociones, generando conflictos internos. En este contexto, las personas entrevistadas han expresado la falta de espacios para compartir experiencias. Aunque las personas se han apoyado unas a otras, hablando de sus propios miedos y necesidades, se expresa una necesidad de algo más, especialmente en el futuro más próximo.

No hemos tenido momentos donde la gente manifieste sus miedos, sus bajones, sus lloros. Cuando digo la gente pues digo el personal auxiliar o yo, y bueno esto nos ayuda a volver a ser un todo.

\subsection{Carga emocional}

Esta dimensión aflora en las conversaciones como dimensión central. El estrés generado en esta crisis se ha sumado al que ya de por sí tienen las personas que trabajan en los cuidados. El trabajo en los cuidados genera una percepción de insuficiencia, de falta y de culpa, que confronta y frustra continuamente nuestra creencia de poder hacerlo.

Ahí es cuando me derrumbé y dije, ostras, lo que está ocurriendo aquí... Luego hay momentos de bajón, de bajón... Luego hay otros momentos que estás neutra porque estás en la tarea y estás centrada en lo que tienes que hacer y ni sientes, ni padeces. Pero luego, de repente, se te remueve el estómago cuando ves que tienen que hacer trece frotis y tienes que esperar el resultado... y ahí se te remueve el estómago y piensas en lo peor y otra vez te da el bajón.

La situación que se ha vivido en los centros ha supuesto una carga de trabajo y una carga emocional mayor de la que había en las rutinas habituales de acompañamiento y cuidados, y se ha mantenido en el tiempo.

Estás más agobiada al final, porque ya llevas el agobio general, para que encima esto, que luego son trabajos del día a día, pero si tú ya vas agobiada de por sí, por ti misma, de todo lo que está pasando, ehhhh, me dicen, me reclaman, si tienen alguna duda, vienen a mí, las dudas de EPI han ido a enfermería, a mis dudas del día a día, rutinarias acumuladas al agobio.

La preocupación extrema por evitar los contagios y proteger a las personas en el entorno residencial ha supuesto largas jornadas de trabajo con altos niveles de estrés. Un tiempo lleno de altibajos, donde ha habido desgaste, evidenciado en el cansancio, la dificultad para pensar y, en algún caso, crispación y derivación inadecuada de la frustración.

Las necesidades del personal auxiliar han aumentado [...], todos los usuarios están en sus habitaciones, hay que dar de comer en sus habitaciones, el tema de las comidas, hay que llevarla a todas las habitaciones, y un sinfín.

Los equipos profesionales han buscado un escape en hacer lo que, por otra parte, resultaba imprescindible, los primeros días con jornadas de trabajo interminables que luego han empezado a normalizarse.

Los primeros días era hacer, hacer, hacer, a las siete, ocho de la tarde, ya cansados, como pollos sin cabeza [...] mal. Bueno [...], intentábamos hacer lo que nosotros habíamos entendido de lo que se nos enviaba de servicios de apoyo, pero muchas veces sin realmente pararnos y ver si aquello que estábamos haciendo estaba bien, no estaba bien... En nuestro caso, ¿esa teoría es aplicable? 0 puede caber el sentarnos y pensar [...] ¿esto es lo único que hay?, las pautas han ido cambiando todos los días.

El entorno también afecta, las noticias, los comentarios, las interpretaciones, etc.

Estás con miedo [....] hay mucha desinformación, por una parte, y demasiada información en la televisión, por otra. En todos los sitios te hablan de lo mismo. Te están hablando en todos los programas, cada uno te dice una cosa [...] yo creo que entras en un bucle.

Aunque las medidas de prevención y control de la infección se iban incorporando a la práctica 
profesional y han llegado a estar más normalizados, la carga emocional y física que han generado en el día a día ha sido elevada. Las condiciones no han sido y todavía no son las óptimas.

[...] cuando me puse la mascarilla, que trabajamos en la UPSI (unidad de psicogeriatría), yo dije, pero esto es inhumano, la expresión no verbal es más importante que lo que estoy diciendo, porque normalmente solucionas mucho con una sonrisa, y ahora, te ponen un parapeto, así, y claro, ellos entre que no ven bien, estás con las gafas empañadas, la cara tapada, no nos escuchamos bien, y dije, ¡esto! ¿Vamos a trabajar así? Luego, cuando tuve ya la percepción de que esto es muy grave, la mascarilla es lo de menos, ahí yo pasé miedo de llevarlo a casa, de traerlo aquí, miedo por mí, con toda esa mezcla tuve una rebeldía interior, estamos haciendo las tareas como si no pasara nada, algo debería estar cambiando aquí, compañeras mías van a desaparecer, si no soy yo, porque alguna se va a contagiar, faltan sanitarios en todos los sitios, en esta situación con gente inexperta, con el agobio que no duermes bien, ay dios mío, ¿están todos bien?, es muy duro trabajar como auxiliar y con los EPI cuando hay un sospechoso, muy duro es, yo sé que el equipo nos entienden muy bien, pero no es lo mismo entendernos que estar ahí, no es lo mismo hacer un aseo que hacer una cura. Meterte en el vapor de una ducha con una EPI completa, que te ahogas entre las dos mascarillas, las gafas, el plástico, aparte del trato humano, la situación física tuya está al límite, sales que me mareo, y esto se añade a todo lo demás, no puedes ir a ningún sitio, yo creo que nuestra labor ha sido muy dura.

Los cierres de algunos servicios como los centros de día y el servicio de valoración de la dependencia entre otros, han supuesto graves trastornos a las familias.

[...] situaciones angustiosas las que me están contando; hablaba ayer con una persona, estaba cuidando a su hermana con un tumor cerebral, a su madre con una hemiplejia, tiene dos críos pequeños, y su mujer que trabaja fuera, sin poder saber si van a tener acceso a algún tipo de ayuda, eso sí es angustioso, y viendo cómo se deterioran.

Es importante señalar la necesidad de incrementar los niveles de tolerancia, comprensión y empatía para bajar la exigencia y el sentimiento de culpa, otras dos grandes compañeras que generan angustia en el mundo de los cuidados.

Hubiéramos necesitado un poquito más de empatía de nuestros compañeros, pues, por ejemplo, sabiendo cómo andamos con los recursos, pues que se rebaje un poquito esta... y cómo está este caso, y qué va a pasar, que le quiero dar el alta... Oye, que ya te he dicho, jayyy! ¡qué mal!, son formas de trabajar diferentes, nos retrasan, ellos no se adaptan a nosotras, somos nosotras las que nos adaptamos a sus formas de trabajar, y claro, es un cambio y depende con quien te pille, pues en fin...

Ante el sentimiento de incertidumbre, aparece la necesidad de certeza. Volver a vincularse a través de restituir la relación, vínculos donde poder reconocerse y, desde este reconocimiento, generar rutinas significativas.

En la desescalada comienza la tensión de nuevo, las personas quieren estar con sus familias, amigos, allegados, y a la vez temen por el contagio por la posibilidad de traerlo al centro. El conflicto interno continúa.

[...] yo quiero estar con mi familia, con mis amigos, tengo muchas ganas, pero si lo hago y ¿si lo pillas?, es el miedo a traerlo aquí, entonces esto a mí me genera tensión y sentimiento de culpa, bueno no es mi culpa, pero sí me siento responsable, es necesario tener el apoyo de los míos, pero también me parece una irresponsabilidad, es algo contradictorio que está dentro de mí.

Situaciones conflictivas en la toma de decisiones que se han superado gracias a la comprensión del momento, pero que pueden aflorar cuando se vuelva a la normalidad.

Ha habido conflicto [...] creo que no tenemos que estar pensando por qué esta no me cae bien, o que sea prejuiciosa. Yo creo que no tenemos que caer en eso, estábamos en lo que estábamos. Tenemos que pensar que si una persona te alza la voz es porque estamos todos en tensión, con miedo, y hay que entender lo que te pueda afectar, y que seguramente si estás delicada, te va a hacer llorar, pues igual también...

Los conflictos han sido una parte importante en la gestión de la frustración.

[...] aquí nos hemos enfadado todas, hemos llorado todos, todos hemos tenido un día de crisis, de buah, ¿qué es esto?, triste, de sentimiento de querer hacer bien mi trabajo pero no poder, ha sido muy duro, muy preocupados por los temas de los EPI, yo me iba a casa llorando casi todos los días, yo no puedo estar delante de todo el personal serena sabiendo que no tenemos material y que tenemos resultados positivos, andamos como andamos, mal, rabia, un poco todo, rabia, tristeza.

El apoyo entre compañeras, poder comentar los casos complicados, encontrar pequeños espacios de apoyo emocional en el equipo y ser escuchadas... Cada persona ha buscado sus propios mecanismos de integración, algunas en el entorno laboral, otras buscando ayuda profesional y muchas incluso en su entorno familiar. La experiencia se ha vivido 
como una etapa de arduo aprendizaje personal y profesional.

En las situaciones de aislamiento preventivo por contacto estrecho con casos positivos, o por convalecencia por covid-19, se ha vivido desde la distancia con menor intensidad, pero con una gran ambigüedad. La frustración por no poder compartir la tarea con las compañeras que están en activo. A estas reflexiones se suma la convicción de poder contribuir a la vuelta con más fuerza.

[...] ya le he dado la vuelta a tener que estar aquí confinada y sé que voy a volver descansada para poder ayudar más a las compañeras que están ahí al pie del cañón.

El hecho de haber vivido esta situación de aislamiento genera una mayor empatía con la vivencia de las personas que están en los centros, una mayor capacidad de comprender.

Las personas mayores todavía lo tienen peor, ellos están cada uno en su habitación, unos con tele otros no, pasar las veinticuatro horas del día ahí solos, porque no podemos darles mucho apoyo, estamos a falta de personal para poder dar un buen servicio, lo que necesitan, muchísimas horas solos en las habitaciones, tiene que ser terrible, yo lo estoy viviendo y es horroroso, tendría que haber un refuerzo. Pasar la vida sin hacer nada [...] no quiero así una vejez, no quiero ese fin para mí, personas totalmente capacitados para hacer un montón de cosas están supeditadas a no hacer nada. ¿Qué más podemos hacer?

Las situaciones de final de vida han generado también estrés en los equipos profesionales. El final de vida se vive habitualmente en los centros con una participación de las personas que tienen relación con la persona que va a fallecer y su familia. Sin embargo, la situación de alarma cambió completamente las prácticas profesionales,

Creo que también llevamos mal la muerte y el mirar desde la puerta y no poder acercarse a dar la mano y esa personalización, esa incluso diría que en más de un momento dignidad, porque claro, cada cuánto tiempo me acerco yo a ver si esa persona siente frío, o está sudando y le tengo que cambiar las sábanas. [...] ¿Qué confort tiene esta persona?, teniendo una persona en situación paliativa en planta, no debe acercarse más allá, no debe tener una relación, pues complicado, complicado, y esto está saliendo poco, si está, pero cuesta hablar de ello. Esto es muy duro, muy duro, estas personas llevan años viviendo con nosotros. [...] Frustración, ¿cómo no vamos a tenerla?

Estamos acostumbrados a los fallecimientos, pero no tantos de golpe. $Y$ de repente es tan impersonal, sin hacerles mucho caso [...] no hay tiempo para que las familias puedan venir, que puedan estar todos de visita, que tú puedas ir a la habitación a estar con la familia, no sé, no hay.

Sí, hay dolor, hay lágrimas, hay sentimientos, hay silencios y una necesidad grande de poder acompañar todo esto y de ser acompañados.

¿Cómo estoy viviendo esto? [...] bueno, al principio, bueno al principio y ahora, esto está siendo muy duro, por lo que se vive, les ves a ellos que claro, echan de menos a sus familias, que no pueden estar, intentas dar todo el cariño posible, intentas hacerte la fuerte, pero sales de aquí y te derrumbas, ya me estoy empezando a derrumbar ahora contigo [...], más de una cuando salgamos de aquí necesitaremos atención seguro, atención psicológica seguro, porque todo te lo llevas a casa y llegas a casa y empiezas a llorar, y empiezas a llorar y te preguntan ¿qué te pasa? pero es difícil de explicar [...] que se te van [...] y [...] no puedes hacer nada. [...] y eso pues un día tras otro, tras otro, me duelen muchas cosas, me duele la forma en que se mueren, la forma en que tienes que sacarles de allí, es muy triste todo, intentas estar con ellos agarrándoles la mano y que no se vayan solos, se les llevan de aquí les clavan la caja y ya está, sin funeral ni nada [...]. Hay situaciones en las que se te rompe el alma, se te rompe el alma.

Y ahora, ¿cómo curamos el resto? ¿Cómo curamos el cansancio físico? Todo el estrés acumulado, toda esta tensión cuando empiece a relajarse...

Es difícil, como profesionales, ver partir a una persona a la que se ha acompañado durante tiempo; quizás haya que aprender que acompañar no es luchar, ni salvar. Acompañar con la intención de mejorar el bienestar, acompañar es estar al lado, disponible. Se requiere presencia, atención y escucha.

[...] hoy ha fallecido una que ya había superado la enfermedad y hoy se ha muerto, después de luchar y sacarla, nada, ves que no... te da muchísima rabia.

Otro vínculo roto como es la prohibición de visitas de familiares desplaza a los equipos la responsabilidad total del acompañamiento, con una incertidumbre acerca de cuál debe ser la actuación profesional en esos momentos, en los que, además, el riesgo de contagio es alto. El sistema de cuidados sin las familias no se sostiene.

[...] me parece muy duro que una hija no pueda venir, que te llame, que su madre ha sido trasladada a las cinco o seis de la mañana y que a las cinco de la tarde te llame y te diga, ¿sabes algo de mi madre?

Las decisiones de las Administraciones Públicas a veces contradictorias con respecto al cierre de servicios, la imposibilidad de derivación o de asignación de una plaza residencial, han 
incrementado las situaciones de estrés profesional provocado por el conflicto interno entre lo que puedo hacer y lo que sé que quiero hacer porque es la necesidad de la persona. Conflictos con las familias, conflictos entre las profesionales.

En nuestro trabajo, por ejemplo, hemos visto que Osakidetza para nosotras ha respondido fenomenal, o sea de reorganizarse, de dar salida, de un hospital a otro, todo como muy bien explicado; sin embargo servicios sociales, han cerrado las puertas, o sea, no hay salidas, y para nosotras que nos toca orientar y derivar, está siendo de lo más complicado a nivel profesional porque es un conflicto importante, estar dando altas al domicilio cuando no son usuarios de volver al domicilio, eso nos está creando mucho conflicto personal y también conflictos con las familias.

Y esto mismo en cuanto a protocolos. Gestionar las fuerzas opuestas del sistema en un "tú a tú relacional", no es fácil, menos en una situación de necesidad y urgencia. La pérdida de autonomía, la pérdida de la personalización. Cuando se está en la urgencia aplicando el protocolo es difícil ver al otro, estos protocolos, en ocasiones entran en contradicción con una filosofía de atención desde la personalización, la autonomía y la dignidad. También se evidencia la seguridad que da un protocolo que ha podido ser pensado por quien lo tiene que aplicar, un protocolo interiorizado.

No estamos acostumbradas a trabajar así, con esta rigurosidad así, de protocolos, de sectorizar, bajo esta campaña de... no médica, es que no sé cómo decirlo, de seguir al pie de la letra lo que nos están diciendo, cuando nosotros siempre cuestionamos todo, siempre discutimos todo, y vamos más allá [...]; esa pérdida de autonomía... ¿Hay que hacerlo?, pues se hace, pero... el protocolo te lo imponen, pero no se ha preguntado a ninguna persona si querían hacerse el test, vienen y hala, y todos al test [...]. ¿No podemos preguntar a las personas si quieren arriesgarse en la vida?

Hay miedo también a contactar con algo profundo que haga derrumbarse, perder el control, y no poder seguir "en la lucha", como si hubiera resistencia a contactar con las propias emociones, ¿Cómo podremos entonces integrar la experiencia para seguir adelante? ¿Cómo podremos empatizar con otro si no lo hacemos con nosotros mismos?

[...] tengo miedo de llegar al fondo y quedarme allí sin poder reaccionar, así que, si tengo que llegar al fondo prefiero hacerlo después de que todo esto haya pasado, miedo a meterme en el fango y no poder responder ahora que se necesita.

Después de esta etapa, cuando se pueda parar, será necesario incorporar estrategias que permitan a las personas descansar, integrar, dar sentido a lo vivido, restituir la relación en espacios para la reflexión y la comprensión, donde se puedan mantener conversaciones tan difíciles como necesarias que nos ayuden a restituir los vínculos, y restituir las rutinas, esta vez desde la calma. Parecen ser tiempos de oportunidad.

[...] trabajando con personas tenemos que estar bien, ahora toca estar más calmado que nunca, ahora no toca alterarnos, no toca alterarnos porque si no, no ayuda en un día a día que tu no estés bien, hay que trabajar, hay que sacar un servicio adelante trabajando con personas.

Para mí ha sido una película de terror, un baile de emociones dentro de mí, todo el rato diciéndome, no rumies, me he acordado mucho del programa de meditación, eso me ha valido para estar serena.

Nos hemos sentido solas abandonadas aquí arriba, las de abajo, la directora encerrada haciendo protocolos, que los tenía que hacer, ¿eh?

\subsection{Cambio y adaptación}

Al principio fue un shock para todos. Desde la comisión de crisis se elaboraron los protocolos que venían de diferentes administraciones, a veces contradictorios, con un objetivo común, salvaguardar la vida. Sin embargo, en organizaciones que trabajan en el marco de la ACP, donde cada persona es única y el abordaje es personalizado, no hay protocolo que sostenga este enfoque ni sistema formal que lo respalde. Se trabaja lo informal para fomentar el vínculo y la relación. Y es que en la gestión de la covd-19, y en aras de la seguridad, se ha desviado el foco de la personalización, del fomento de la relación, del vínculo, se han roto rutinas, sacando a las familias y voluntarios de ellas. La percepción de confianza y certeza disminuye, así como la percepción de bienestar.

\footnotetext{
Los primeros días dices, bueno vale, vamos a hacer, seguimos los protocolos, luego los nuevos los tenemos que estudiar, y cada vez los van cambiando de día a día. Vino Arantxa, nos dio la formación, súper bien, pero es que claro, desde la propia diputación y Osakidetza iban cambiando los protocolos porque ellos van también a ciegas. La sensación es que nosotros también íbamos un poco a ciegas [...], empezamos con una visita de una hora al día, llamamos a todo el mundo y de repente a la tarde recibimos un correo, que no, que las visitas se han cancelado. Vuelta a empezar, claro, hay que avisar a todas las familias, nos quedamos hasta tarde avisando.
}

En todas las conversaciones se hace referencia a la exigencia de adaptación en esta etapa de pandemia. Los profesionales han tenido que adaptarse a las circunstancias constantemente, y a ello ha ayudado 
el paso del tiempo, el apoyo encontrado en el equipo, la información recibida, la percepción de certeza que ofrece todo lo anterior y que de alguna manera encamina la aceptación de la realidad. La adaptación al cambio se vive como un proceso en el tiempo.

Una primera etapa, en febrero-marzo, en la que empezamos con las medidas, se prohibió la visita a las familias. Hoy te lo pongo en color naranja porque veíamos el peligro, pero no sabíamos hasta qué punto iba a venir, qué iba a pasar luego, a la segunda etapa marzo-principios de abril. Las noticias tan terribles que hemos tenido, hoy te lo pongo de color rojo, rojo. La etapa de miedo ha seguido y ahora estamos en el color verde. Estamos viviendo una etapa de esperanza que vamos a recuperar, van a recuperar sus vidas, vamos a recuperar nuestras vidas y todo va a ser como antes. La siguiente etapa, azul, sería la calma, la tranquilidad [...], la normalidad, la rutina, la vuelta a nuestras familias, un poco de visitas, la vuelta de nuestros voluntarios...

Cuando se suspendieron las actividades del voluntariado y las prácticas profesionales, se empezó a vivir una sensación de incertidumbre en los centros. Pero en el momento en que se prohibieron las visitas de familiares, se generó un miedo importante entre las personas residentes al no poder contar con ellas. Esta etapa dio lugar a una tercera en la que personas mayores y profesionales empezaron a adaptarse a las nuevas rutinas y a tener esperanza de recuperar sus vidas. La esperanza en la recuperación de la normalidad es un acicate que ayuda a seguir adelante.

Sí, sí, aguantamos, porque sabemos que pronto volverá la normalidad, eso queremos, que las cosas sean como antes.

La percepción del cambio es diversa, incluso se perciben cambios positivos, abriendo nuevos horizontes.

Nosotras hemos vivido más el cambio, veníamos de una unidad donde todos tenemos la misma filosofía y de repente tenemos que volver a subir que es de donde nos fuimos con una situación muy compleja, pero creo que ha sido positivo. Yo no estoy trabajando con mi equipo habitual, las echo muchísimo de menos, porque todas hablábamos el mismo idioma, el hecho de que el control esté en mitad de la planta hacía que el contacto con los pacientes fuera constante, solíamos tener tres y cuatro sillas para los pacientes que se sentaban allí, eso no ha sido así en esta nueva situación. No he tenido enfermeras del equipo conmigo, pero si a todas las auxiliares y con ellas no me he sentido sola... cambios físicos, todos.

Los cambios han afectado también a los calendarios de los profesionales, derivados de las medias de adaptación y recomposición de los equipos, como de la necesidad de conciliación familiar. La vuelta a la situación anterior es esperada y ayuda a tolerar los cambios.

Aquí hay muchas enfermeras que se les ha cambiado el calendario totalmente de arriba a abajo, y no ha habido la mínima protesta, porque es una situación especial, y todo el mundo entiende la diferencia que hay, sabemos que todos volveremos a la situación anterior y esto hace que todos toleremos bien los cambios que está habiendo.

Ha sido un periodo de cambios constantes, al principio centrados en la tarea, sin orden y con sensación de caos. Pero poco a poco, los equipos han ido adoptando los protocolos y se han adaptado a las nuevas rutinas. Las profesionales se han adaptado de una forma rápida, asumiendo diferentes roles tanto en la preparación de nuevos espacios físicos como en procurar mantener los vínculos que generan bienestar.

Estamos más centradas en videollamadas y en informar a las familias, nos dedicamos también a eso.

Se generó una unidad móvil en la primera planta. Entonces teníamos claro que la teníamos que vaciar porque ya teníamos tres habitaciones libres en esa unidad y se eligió esta porque había oxígeno en la pared [...]. Entonces era poco a poco ir vaciando esa zona. Es un pasillo largo, empezamos desde el fondo [...] y decíamos hoy a quiénes vamos a cambiar y qué movimientos podemos hacer, las rutas, mirando toda la casa y cómo lo teníamos que ir cambiando...

Todos estos cambios se han realizado gracias a la participación, buena voluntad y expectativas de volver a una normalidad, tanto de profesionales como de las personas que viven en los centros y sus familias.

La gente se ha adaptado muy bien, pero el mensaje no ha de quedar ahí, porque nos hemos dado cuenta de que se ha perdido mucho, quizás hay gente con más cinchas, porque la estructura física del módulo así lo requiere, que no esté cerrado genera problemas, que no vengan familiares es un añadido, ellos por su situación necesitan el contacto afectivo de los suyos. ¿A cuántos de ellos dejamos entrar, a uno, a dos, quién sé, quién no?, es un tema secundario al proceso que hay, pero hay que gestionarlo también. Toda la gestión de lo que se pierde y de los riesgos es una cosa que estamos asumiendo nosotros.

A esta reorganización de espacios se sumó la gestión de los fallecimientos. Personas que llevaban años viviendo en una habitación y tuvieron que ser trasladados en sus últimos momentos.

Y luego los positivos que iban saliendo se intentaban derivar, pero si no, había que ir 
bajando a la primera. Mientras tanto, gente que falleció y entonces a esas personas también, por sus enseres, sus cosas, también nos interesaba vaciar esa habitación, desinfectar, y seguir vaciando...

Se limitaron los movimientos de profesionales del equipo interdisciplinar para evitar su rotación entre unidades y disminuir el riesgo de contagios cruzados.

Hemos estado ayudando a enfermería cuando hacía falta, porque se puso toda la casa a coger temperatura y saturación, con todo lo que eso supone. También se puso un refuerzo de enfermería, pero aun así se requería de mayor apoyo [...]. Lo que nos ayudó, creo, fue que a primera hora de la mañana nos reuníamos todos y veíamos qué había que hacer y nos repartíamos todas las tareas.

Destaca la capacidad de adaptación que han tenido las personas residentes, cumpliendo los protocolos y aceptando el devenir.

[...] ¡tienen un poder de adaptación! [...] un ejemplo a seguir, ellos los primeros, y luego las familias también.

La capacidad de cambio y la adaptación en la urgencia han sido posibles por la implicación de las personas. No obstante, esta adecuación abrupta que ha implicado cambios de rol importantes, largas jornadas y niveles de estrés elevados, ha de ser sostenible en el tiempo. Debemos pensar cómo normalizar en nuestro día a día esta situación para poder seguir trabajando en el acompañamiento a las personas para mejorar su bienestar.

\subsection{Sentido de pertenencia, propósito y equipo}

Se identifica el trabajo en equipo en torno a un propósito común como fuente de bienestar y reconexión con el para qué estamos aquí. Es también fuente de satisfacción al estrechar las relaciones humanas tanto dentro del equipo como con las personas residentes y sus familias.

Hay testimonios en casi todas las conversaciones del sentido del para qué estamos aquí, a qué nos dedicamos, el propósito de acompañar a las personas en su proceso para mejorar su bienestar, y ese contacto tiene que ver con poder ver a las personas, no a las personas como grupo, sino a cada una de ellas como tal para vincularnos.

[...] no sé realmente lo que ocurre ahí, sí que tengo muy claro en qué momento ocurre, dónde teníamos que atender a una persona y nadie lo hicimos, y ... jostras!, si nosotros nos dedicamos a esto, [...] no nos dedicamos solo a lavar la ropa, o a atender solo a familias, a cambiar de habitación, a seguir el protocolo, no nos dedicamos solo a rellenar planillas, nos dedicamos a acompañar a las personas, y a esta mujer le teníamos que haber sacado de esta habitación, o no, pero lo que está claro es que algo que todos y cada uno de nosotros entendíamos que es la prioridad para nosotros, las personas que viven en el centro, nadie pusimos delante de nuestra tarea y nuestra actividad, [...] cada uno estaba con lo suyo.

Cuando ella entra en nosotros como ella, cuando la podemos ver, es cuando nos damos cuenta. Por supuesto que la encargada tiene que tener la ropa lista, la directora las planillas hechas y la enfermera las curas a tiempo, eso tiene que estar, pero... ¿qué está por delante, las personas o la tarea? Creo que como las auxiliares son las que atienden las necesidades en primer orden de las personas, nosotros como equipo despertamos, y nos dimos cuenta de que tenemos que priorizar más que nunca, a esta persona, a esta otra, a la que da positivo, a la que está en una situación paliativa y a su familia, a la que va a un hospital le tenemos que dar el móvil para que pueda hacer llamadas, y su neceser, la personalización, dejar de atender al grupo de personas mayores y atender a la persona.

Las personas han mostrado su lado más humano, lo mejor en aras de la tarea diaria.

Porque lo que necesitamos es estar todos juntos, unidos, y yo creo que lo hemos conseguido. Lo estamos consiguiendo a todos los niveles y creo que, gracias a eso, pues esto pasará pronto. Yo personalmente lo necesito.

Yo creo que la voluntad de todo el mundo se nota, aquí a muchas enfermeras se les cambió el calendario totalmente de arriba abajo y no ha habido la más mínima protesta. Y eso está bien, porque es una situación especial y todo el mundo entiende la diferencia que hay.

Los problemas que han surgido en cada momento se han resuelto hablando, buscando soluciones entre todos. Ha habido claras muestras de tolerancia, solidaridad y aceptación de las situaciones, respetando los ritmos de cada persona. Nuevos roles, nuevos equipos, soluciones distintas para nuevas necesidades.

Si es estar todos en la reunión y ¿qué hace falta hoy? Que todo el mundo estemos arrimando el hombro y decir que estamos. ¿Qué hace falta? ¿Qué hay que hacer? Que todo el mundo levante la mano ya.

La situación no solo unió a los equipos profesionales, sino que además embargó a todas las personas de una sensación de pertenencia a algo superior.

Lo que no se había visto antes. Porque antes igual hola y adiós. Y no conocías prácticamente a los vecinos muchas veces. $Y$ ahora sales $y$ todos juntos aplaudiendo. No por esta causa, por los sanitarios o por los cajeros, o por los 
transportistas o por los médicos, los policías, es igual, pero estamos todos unidos.

No toco nada en el portal; por ejemplo, no utilizo el ascensor porque estoy pensando en mis vecinos a los que tengo que cuidar.

Pertenecemos todos a esto, o sea, estos son nuestros mayores, estos son nuestras familias y este es nuestro equipo, nuestro objetivo.

El sentimiento de pertenecer a algo en lo que cada uno tiene un sentido en sí mismo y lo tiene también para el equipo, para la unidad, donde lo que se da y lo que se recibe está en equilibrio.

[...] para el trabajador un cambio es lo mismo, es la sensación que tengas tú de estar en la fundación, cuál es mi sitio, cómo participo en esto, si soy más o menos importante o si quiero serlo o no [...]. Matia te da mucho, tú has elegido venir a trabajar y con sus cosas buenas y malas y si no vete a otro sector, no puedes trabajar amargado, si no, cambia...

Las personas que viven en los centros han demostrado también sus ganas de luchar, su necesidad de contribuir y sentirse útiles, contribuyendo al bien común. El propósito de los equipos profesionales ha sido mantener los vínculos con las familias y las actividades significativas para las personas usuarias recomponiendo sus rutinas.

Tenemos alguna señora que ahora, por ejemplo, estamos con el rosario, todos los días rezamos el rosario. [...] Otra nos ha dejado el piano, ella dice que se siente mejor porque estamos tocando su piano y gracias a ese piano, por la tarde, escuchan música los que quieren. También hacemos sesiones de cine y el otro día nos ayudó a elaborar una lista de películas de los años cincuenta y sesenta.

Profesionales de otros servicios han apoyado en la cobertura de necesidades en los centros residenciales donde ha habido contagio y más bajas del personal.

[...] el sentimiento de pertenencia [...], yo recuerdo algún comentario hace tiempo que personas de rehabilitación no sabían que aquí teníamos un centro, pues esta ha sido una oportunidad muy buena para conocer este centro, conocernos las personas, que aún tiene mucho más valor, de ponernos cara.

Se pone en valor la atención personalizada, en unidades pequeñas, los equipos pequeños, la no rotación, el rol de la profesional de referencia y la de la coordinación de módulo; en definitiva, se pone en valor todo aquello que propicie vincularse desde la relación.

Me gusta el trabajo de equipo, somos tres o cuatro en función de los turnos, pero también me gusta individualizar los grupos, grupos más pequeños, para que puedas estar con menos personas, pero mejor; cuando esas horas muertas están por ahí colgando, estar con tres residentes haciendo algo que les gusta, y para nosotros es importante porque aportamos mucho más [...]. La gente rota cada vez menos, la rotación es un punto en contra, conocen a toda la casa, pero a la vez se pierde conocimiento del día a día, mucha información se pierde en el camino.

También está la importancia de conocer a las personas, de saber sus gustos, sus preferencias, su historia de vida, sus inquietudes, sus ideas, sus afectos, su necesidad de trascendencia.

[...] cuando estoy en la ducha, y le pregunto, ah, ¿qué perfume te gusta?, porque veo que tiene perfumes en la habitación, y me cuenta. Ellos saben de nuestra vida también, y nos preguntan, para mí es muy gratificante, y que me cuente, para ello hay que tener tiempo, [...] me acuerdo de un día que llevaba tiempo quejándose de la cena, y dos personas me decían que comerían un par de huevos fritos, que desde que estaban aquí no habían vuelto a comerlos, bueno, pues al día siguiente preguntamos si querían y preparamos la cena en la cocina de la unidad unos huevos fritos para quien quiso. Bueno, pues a mí cuando haga buen tiempo me gustaría ir a la Antigua, bueno pues lo preparamos también. A mí a misa, pero a la del pueblo, bueno pues con voluntarios lo hicimos. Tienes que indagar y compartir con el equipo esta información, y tener en cuenta que no a todo el mundo le gusta lo mismo, tienes que interesarte por su vida.

El apoyo del equipo se evidencia como una clave fundamental.

En el equipo siempre nos han aplaudido el trabajo que hemos hecho y eso me ha hecho sentirme muy bien.

Destaca así la importancia del equipo, el sentimiento de pertenencia a un equipo donde uno puede apoyarse y dar apoyo, contener y ser contenido, encontrar reconocimiento y ofrecerlo, preguntar lo que no entiende, encontrar otra visión y aprender.

[...] en todas las guardias un mensaje de todas, qué tal, qué tal vas, al final te anima, te ríes, hablas, ese apoyo, que es importante y lo hemos tenido.

\subsection{Actitud positiva y confianza}

La actitud positiva basada en la confianza en uno mismo, en el equipo, en la organización, en la vida, ayuda a superar el día a día, dando sentido a lo vivido.

Menos mal que me llevo lo positivo porque ha sido mucho más positivo y, de hecho, creo que se ha hecho un trabajo brutal desde todos los 
departamentos. Yo también percibo que se ha hecho un trabajo increíble, increíble. Y los que están al pie del cañón...

Creo que en las crisis las personas se fortalecen [...]. Nos refuerzan estas situaciones, yo me lo planteaba así, como una etapa en la que hay que dar lo mejor de cada uno.

Bueno, pues a través de las noticias, todos los días intentas hacer una lectura del periódico contándole cómo están las cosas. Intentamos buscar buenas noticias positivas y siempre comparar con el día anterior. Luego hablan con sus familias, pues les dicen, bueno, ya estoy empezando a ir a trabajar, ya no estoy todo el día en casa.

[...] y siempre pensando en positivo, intentamos hacer reír, con algo de humor, que tengamos la mente ocupada, que no estén pensando en la covid todo el rato. Ahora nosotros somos su familia.

También hemos ganado en confianza, [...] estamos saliendo o hemos salido, no sé si airosos es la palabra, pero sí hemos tenido capacidad suficiente, creatividad, imaginación, recursos como para de alguna forma dar respuesta.

Destaca la actitud de las profesionales de servicios no residenciales, rehabilitación ambulatoria, valoración y centros de día, que han venido a apoyar a los centros donde se les ha necesitado.

Las ganas, la actitud que le están poniendo las profesionales de rehabilitación y valoración en el centro, este valor que decimos en nuestra organización que es la actitud positiva.

Preguntando directamente sobre las características de los equipos que se formaron en las unidades covid-19, destaca el compañerismo, el buen humor, las ganas de generar buen clima para que las personas que están allí viviendo estén mejor, mejorando el bienestar, pudiendo apreciar lo que sí es, mirada apreciativa.

[...] es un grupo, vamos, súper humano, súper divertido, nos divertimos mucho dadas las circunstancias, nos procuramos divertir mucho, somos muy pasayas todas, y todo esto también ayuda a unirnos, un poco de humor no quiere decir que sufras menos, cantamos y bailamos juntos con las personas que quieren hacerlo, y esto nos anima a todos. Yo estoy encantada, si no fuera por la situación yo me quedaría aquí toda la vida.

La necesidad de incluir la diversidad, la diferencia, de integrar lo positivo y también lo negativo, la carencia y el exceso, el conflicto y la calma, de ambos lugares se obtienen aprendizajes.

A mí me gustaría que reflejarías lo positivo, sí, pero también lo negativo, porque de todo se aprende, y seguramente esto volverá y nos pilla con el trabajo hecho ¿no? [...] pensar en las carencias que hemos tenido y que eso se pueda subsanar en otra ocasión.

\subsection{Información y comunicación}

La comunicación se entiende como un elemento clave en el bienestar de las personas que viven en los centros; la comunicación también genera vínculo. Siendo algo bidireccional, para que sea comunicación es necesario el feedback.

Para mí la comunicación es un punto súper importante en cuanto al bienestar psicológico de nuestros residentes [...], porque si ella, que es de aquel pueblo, habla a las cuatro con su hija por teléfono, en la planta crea un ambiente diferente. No está gritando en la planta. Y la que está al lado, está más tranquila...

[...] veo que hay cosas que se han quedado, como la mascarilla que ya se ha quedado, y ya me da pena, porque ya le he dicho hoy al médico en la reunión general, que en plan sanitario, por supuesto que será buenísimo para evitar muchas cosas, pero en plan social, aquí, en nuestra comunicación con ellos, hemos dado bastante un paso para atrás, nos cuesta comunicarnos, y esto hace que te sientas peor en tu trabajo diario... me daban ganas de quitarme todo y decirles que soy yo, la de siempre, yo.

Los canales de comunicación, el WhatsApp, el correo electrónico, ante la escasez de contacto, se demanda el contacto también en el acto de comunicar.

[...] la comunicación no es fluida, y te dicen, ya hemos puesto en el correo, ya hemos puesto en el correo, pero no es en el correo, pero por favor, un poco de contacto, sube y coméntalo, una frialdad y no sé, no sé, en este estado no hemos trabajado nunca, que suban las enfermeras y no te miren...

La información, como base de la certeza y la confianza, también abarca al comité de empresa, como representantes de los trabajadores, como tractores ella, desde un lugar activo como agentes de información.
[...] mínimamente, teniendo en cuenta la excepcionalidad de la información, haber estado informados, yo puedo llamar, pero para seguir participando tengo que recibir del otro lado, tampoco nos hemos reunido nosotros.

En la trasmisión de la información es importante la estructura informal y también la estructura formal, se pone en valor una figura comunicadora, trasmisora de información.

[...] hemos protocolizado mucho nuestro trabajo, la reunión del office es muy importante, antes ahí 
hablábamos de cómo distribuirnos el trabajo y genial, qué bueno sería que hubiera una persona durante todo el turno, de coaching, como se dice ahora, hablando con todos, yendo por ahí ¿cómo vas?, alineando todo, diciendo cómo, siete horas con alguien que te ayude.

Un buen diseño del flujo de información, y la confianza en este flujo, ayuda a no generar cuellos de botella, malentendidos y "chascarrillos"; en definitiva, ayuda a mejorar la eficacia grupal.

Para poder trasladar a los equipos profesionales los continuos cambios en los protocolos de actuación se organizaron grupos de trabajo y reuniones informativas que generaron en algunos momentos sensación de descoordinación y, en otras ocasiones, las más, han sido fundamentales, produciendo bienestar.

A las cuatro y media o cinco de la tarde vamos a sentarnos para ver qué está pendiente de hacer de lo que hemos planificado y si eso aparentemente puede esperar o no puede esperar, porque los primeros días era hacer, hacer, hacer por hacer a las siete u ocho de la tarde, ya cansados, como pollos sin cabeza, mal...

En ocasiones se ha percibido el desconcierto de las familias por la información que desde el centro se daba, en contraste con las informaciones de los medios.

[...] con las familias, yo he tenido sentimiento de que a veces han tenido desconfianza de lo que les contábamos, porque la televisión y los periódicos nos han vendido que somos las residencias centros muy opacos, que no contamos la verdad; bueno, yo he estado en casa escuchando la televisión y me llevo las manos a la cabeza porque hablan con si fuéramos, vamos [...] y noto que me dicen sí, oye, pero ¿mi madre está bien?, ¿seguro?, ayer la encontré un poco apagada, es que me dijo que no merendó y bueno, así, notaba desconfianza, ya va cambiando la cosa.

Por otra parte, se evidencia cómo en los espacios pequeños hay más interrelación y cómo se va generando una cultura diferente en cada entorno.

Esas cuadrillas tan cerradas que había antes ahora están desapareciendo, se están abriendo, hemos generado dos entornos, primera planta y segunda... Los salones son los mismos en los que estaban, pero la cosa ha cambiado, ya que son entornos más pequeños.

Los profesionales, ante la pregunta de qué les ha facilitado tener una buena comunicación en el equipo, comentan que esta comunicación se relaciona con el estar, con la relación.

[...] yo creo que, en la organización, la comunicación, tanto con la directora como con el resto del equipo y mis compañeras, siempre hemos tenido una buena relación y mucha comunicación, estamos constantemente, y eso no ha cambiado con la covid, si antes teníamos mucha comunicación, ahora simplemente más con todo este tema.

Se pone en valor la adecuada elección de los espacios físicos, temporales, así como la interlocución.

Entonces creo que estaría bien nombrar a una persona de la dirección, de manera que recoja toda la información, y hacer un pequeño resumen diario, con el cambio de procedimientos, otro de prevención, otro de no sé qué... Porque claro, estás haciendo un cambio de habitación y te llaman y estás hablando con la familia por teléfono, y te llaman... ¿es que no ves cómo estoy?

Se pone énfasis en la necesidad de una gestión estructurada y jerarquizada de la información para tranquilizar a los equipos profesionales en cada momento y mejorar la percepción de certeza.

La cuestión es que desde el primero hasta el último día se tenga como una estructura en que sepamos que todo el mundo se va a enterar de aquello que gestionamos, un flujo de información [...] que existieran un par de figuras, una figura por planta, que dé una buena información y que se preocupe del bienestar de los que están y que la que no ha podido venir por la mañana porque estaba de tarde sepa dónde o a quién acudir para decirle...

Y se destacan los canales de información, cuadernos de enfermaría, grabaciones, WhatsApp, reuniones con todo el personal, etc.

En enfermería tenemos todos los protocolos puestos, y explicados; los escenarios, en cuanto se cambiaba de escenario se cambiaba todo y además se ponía en el parte, cambio de escenario que afecta a tal y los teníamos ahí a la vista.

[...] nos han ayudado un montón las reuniones con todo el personal, los archivos disponibles en las computadoras nos ayudan si no hemos podido estar en la formación, hemos grabado y enviado a compañeras que no estaban.

Una vez más el paso del tiempo y el contraste de la información van modulando y asentando la percepción de seguridad y confort, y reforzando el aprendizaje.

Los bulos que van corriendo fuera también ocurren dentro; por ejemplo, estás en la segunda y de repente baja una y dice, en la cuarta está todo el mundo con mascarilla, y dices, ¿cómo?, ¿y nosotros no? Aquí no llevamos nadie, ¿qué ha pasado? ¿qué ocurre?, eso entra dentro de la información veraz que dice él, eso hace mucho 
daño, luego con las explicaciones que nos daban abajo pues ya nos tranquilizábamos.

Con la formación continua, de cómo lavarnos la manos, cómo protegernos cuando estornudamos, cómo colocarnos las protecciones, compartir experiencias, uno se siente bien, nos sube la autoestima, porque nos sentimos apoyados también, nosotros también entendemos que no ha habido equipos, como en el caso de las mascarillas al inicio, que teníamos que usarla dos días, ahora ya por turno, como trabajador ya sabemos la situación, no podemos culpar, nos adaptamos a lo que tenemos, no es cosa del centro, no es cosa de un presidente, es a lo que venga, porque si vosotras nos cuidáis a nosotras, nosotras podremos cuidar a los residentes, es una cadena.

\subsection{Reconocimiento}

El reconocimiento de la diversidad se pone de manifiesto en la satisfacción de las necesidades de cada quien, incluso en cómo se ha vivido la crisis.

Hay personas que han querido estar en la habitación, más aisladas; otras que querían luchar contra el virus junto con nosotros, otras que querían ayudar, leían con quien no podía ver, rezaban el rosario, etc., de todo, como nosotros.

El reconocimiento también se evidencia en la contribución de cada uno.

Hay personas que necesitan sentir que son útiles también, yo diría que todas, ayudando, aportando lo que quieran; por ejemplo, ayer le dio un mareo a una residente y llamamos a la médica de guardia, y hay una persona en concreto que siempre está dispuesta ayudar, y estuvo acompañándola todo el rato, y se lo decimos, tú ayudas mucho. Estamos con las meriendas y siempre ayudando, poniendo los zumos, y ayudando [...] ejerciendo su autonomía.

El reconocimiento a la persona a través de la escucha de su historia de vida, sentirnos reconocidos al sentirnos escuchados, al ser vistos en los ojos del otro donde surge la percepción de ser reconocido, y en este reconociendo estamos promoviendo la dignidad.

Cuando te cuentan su historia, una vida apasionante, y se motivan, se sienten como grandes, porque tú le estás escuchando y ha sido su vida, cada persona tiene su vida muy importante, y a veces se desconoce lo importante que es escucharlas, nosotros como sanitarios, como auxiliares, tenemos que saber escuchar. Escuchamos todo lo que podemos, pero no es suficiente, sobre todo cuando ves a alguien con los ojos brillantes que está motivada porque te está contando algo que para esta persona es súper importante, se tiene que sentir importante, así que, si no te da tiempo a hacer algo, pues nada, ya lo harás más tarde.

Y aceptarnos con todo lo que somos, podernos ver "nos" y aceptar "nos" en las luces y las sombras, esta experiencia ha sacado lo mejor de nosotros mismos, y necesitamos dar cabida también a la otra parte menos luminosa, esto hay que acompañarlo también.

Ahora estamos muy unidas como equipo, y creo que cuando la cosa se calme, no sé si llegaremos a que la cosa sea normal, yo creo que al final esto se enfriará, yo no soy de las que pienso, aaay esto lo vamos a mantener... no, las cosas se enfriarán, volveremos a tener una vida más normal, y eso hará que entonces aunque esto nos ha enseñado lo importante que es la salud, estar bien, pero soy relista y que tendrás que volver a venir a hacer cursos, para que los equipos nos llevemos bien, porque somos personas y tenemos nuestras cosas que salen en el trabajo, salen en casa, los conflictos volverán a salir.

El reconocimiento horizontal, entre pares del equipo, tan importante, surge como un gran valor en esta crisis. El reconocimiento profesional se asocia a la entrega total, a la generosidad con la que se han llevado a cabo las tareas del cuidado y a la capacidad de adaptación de los equipos profesionales a la situación de alerta permanente.

Mis compañeras también trabajan muy bien, y se lo digo cada día.

La gran mayoría lo han dado todo, lo mejor que tenían dentro... volver a la planta y ver al personal entregado, contentos de realizar el trabajo que están haciendo, implicados, atentos y que controlan muy bien todo lo que es la patología, el conocimiento de los familiares, el manejo farmacológico [...], para mí ha sido muy positivo. De lo que me doy cuenta es de que el trabajo de auxiliares y enfermería es el puntal más importante en esta unidad, el médico ajusta, pero el peso lo lleváis vosotras, la responsabilidad que asumís.

El día que vinimos, mantenimiento se lo curró toda la mañana para colocar el control de errantes, cosa que me habían dicho que era imposible; lo pusieron, hicieron lo indecible para poner las cámaras, que costó unos días, pero lo hicieron y la verdad es que todo este trabajo de ellos nos ha dado seguridad.

[...] la verdad es que estoy contenta con el trabajo que estamos haciendo, hemos hecho una piña, nos llevamos muy bien y te das cuenta de la calidad humana de muchas personas.

Después de esto, yo no sé ni quién, ni cómo, ni de qué manera, ni cuál es la forma, pero se debería 
aplaudir a todo el mundo, a todos, a todos, desde el que más manda al último mono, de alguna manera, no sé cómo, hay que darle una vuelta. Yo creo que el ser humano necesita, y más cuando está dando tanto, necesita un reconocimiento, eso es muy bueno, el ser humano necesita que se le diga que está haciendo las cosas bien.

El reconocimiento se ha expresado en la oportunidad de conocer a cada persona, cuando en el día a día pueden pasar desapercibidas.

Estoy contenta por haber tenido la oportunidad de descubrir a las personas, pero, por otro lado, [...] que tengamos que pasar por esto para descubrir a las personas, qué digo, soy yo quien no ha tenido capacidad de ver esto y esto realmente existía.

El reconocimiento de los familiares a través de palabras de apoyo, de preguntar cómo estamos también, de verbalizar que compartimos los cuidados.

[...] hay familias que te animan mucho, que preguntan, ¿y qué tal estáis vosotros, cómo lo estáis llevando vosotros?, que te digan y vosotros ¿cómo lo lleváis?, mucho ánimo, y te dan las gracias, jo, ¡lo estáis haciendo muy bien, hombre! Eso es un subidón, porque al final te están entendiendo, que en esto estamos todos.

[...] ahora que ha pasado ya mes y medio, la cosa va cambiando, en todas las llamadas y videollamadas los familiares nos han felicitado y han agradecido mucho nuestra labor, han cambiado la perspectiva porque han visto que ya ha pasado un mes y medio, y han visto que las cosas que hemos dicho que son así.

Se ha apreciado el reconocimiento social en forma de aplausos diarios a los equipos profesionales del sector sanitario.

La valoración que se les ha dado ahora a los sanitarios y que antes no tenían, que la gente valora más a los sanitarios, a la sanidad, se ha visto ahora de otra manera.

Finalmente, se reclama priorizar el reconocimiento social hacia las necesidades de las personas que viven en los centros. Las medidas de control del riesgo de contagio han estado por encima del bienestar de estas personas y del buen trato hacia ellas.

El trato social hacia la persona mayor no me ha gustado, esto me ha enfadado mucho. Se han visto las videollamadas en la televisión cuando nosotros llevábamos quince días haciéndolas, en la desescalada han sido los últimos, deberían haber sido los primeros en poder salir, por encima de los niños. Todos tenemos los mismos derechos. Nosotros hemos hecho lo que hemos podido para que estén bien, escuchando sus preferencias, observándolas.

\subsection{Lugares de encuentro: construyendo vínculos}

La palabra nos da significado a lo vivido, ayuda a elaborar la realidad. En todas las conversaciones ha salido esta necesidad, sentirse escuchado, darse cuenta de todo lo que hay para decir, para aportar, para construir con otros, para compartir. Poder darse cuenta de la conexión tan grande que se tiene con el propósito, con lo vocacional, de la fortaleza interna, poderse escuchar ayuda a comprender "nos", a querer "nos" un poco más.

Me va a venir bien sentarme y reflexionar un poco, ¿cómo estoy viviendo esto?, porque me haces la pregunta y sin pararme a pensar no lo sé, lo primero que me surge decir es [...] centrados en la actividad, en la actividad, en el hacer, hacer, sin observarnos a nosotros mismos, el objetivo es estar, trabajar, hacer lo que hay que hacer, sin muchas veces sentarnos y pensar [...] algo que [...] he descubierto al cabo de una semana de empezar esta crisis. A las cuatro y media, cinco de la tarde, vamos a sentarnos para ver qué es lo que está pendiente de hacer de lo que nos hemos planificado y si eso que está pendiente puede esperar o no puede esperar.

[...] cuando me dijeron que ibas a venir y nos ibas a hacer unas preguntas, me pareció bien, y yo siempre estoy dispuesta a contestar y hablar del tema, pero no pensaba que iba a ser tan importante, que iba a ser tan bueno, esta conversación que hemos tenido aquí, que teníamos tanto para contar, que teníamos todas ahí todo lleno, y te quiero agradecer porque ha sido un sitio donde alguien que me escucha me va a comprender, porque fuera de aquí no puedes hablar de esto, entre compañeras bastante me entienden pero todas estamos viviendo lo mismo, entonces, desde alguien que no sea mi compañera, en el sentido del día a día, y que me pueda entender lo que le estoy contando a la primera, sin tener que dar muchas explicaciones, así que un aplauso, yo creo que esto lo tenemos que hacer de vez en cuando, es muy buena labor.

[...] este ratito me ha servido de mucho, me he desahogado un poquito, oye, me he dado cuenta de cosas que tengo buenas, hasta ahora sabías que estaban ahí, que ibas echando mano de ellas, pero que no te dabas cuenta de que me ayudan tanto, no pensaba yo que era tan fuerte.

También se recalca la bondad de poder hablar con alguien de "fuera", al que no ves todos los días. Ayuda también ser escuchada libre de juicio y desde ahí poder pensar.

[...] hay cosas que tienes ahí y que las sueltas con tus compañeras, poder decirlo a alguien [...] de fuera, que todos los días comentas con tus compañeras, parece que mira pues me ha venido bien...

La necesidad de espacios para la escucha y la gestión de emociones se ha derivado de una sucesión de 
cambios que obligaron a los equipos profesionales a una adaptación permanente y al procesamiento de situaciones que en muchos momentos han escapado de su control.

[...] sí que se ha dado la opción de lugares para expresarse, de solucionar dudas con el tema de los EPI, los martes cogimos ese foro de poder escuchar las preguntas, las intrigas, nos iban explicando por parte del equipo en cuanto a lo sanitario, cómo se hacían las cosas, nos ha venido muy bien y, bueno, los protocolos han ido cambiando a las tres de la tarde, a las nueve, eso peor, pues eso. La enfermera nos ha dado mucha seguridad, el perejil de todas las salsas.

A través de los espacios que nos damos, donde en el equipo compartimos la acción y la pensamos, vamos adquiriendo unas nuevas rutinas que nos va dando seguridad, certeza, es el proceso de aprendizaje.

[...] sí, vamos a reunirnos, vamos a pensar para poder coordinarnos, [...] con esto hemos podido coger una nueva rutina ¿no?, cada uno tiene su espacio, sabe cómo, ¿no?, tenemos una nueva rutina, [...] hemos cogido un nuevo orden.

También se trata el orden como necesidad en el caos, encontrándolo en los espacios para poder pensar, gestionar las emociones y trasformar la acción.

Yo creo que capacidad de trabajo la tenemos todos, lo que pasa es que un poquito de orden, el orden, cada uno tenemos nuestra forma de trabajar, un poco de orden y de coger aire, vamos como caballos locos, estoy acelerada porque estoy enfadada, porque no puedo hacer mi trabajo, y no lo estoy haciendo bien, no tengo herramientas. Yo creo que ayudaría tener reuniones, tenemos el intercambio de información puntual. Cuadrar el trabajo de médico, enfermera, auxiliar, sí que estaría bien, sí. En su día teníamos las reuniones de equipo, pero llevamos mucho tiempo sin hacer, en algunas plantas sí, pero en otras no. Y no solo para hablar de trabajo, sino también para hacer lo que estamos haciendo ahora, ¿qué tal estáis?

Es importante el consenso o pacto en el equipo de cara a las actuaciones profesionales y a poder compartir la responsabilidad, comprender la información, dotando de significados comunes a lo que ocurre, generando un entramado relacional a través de la palabra pensada en colectivo, haciéndola nuestra, un entramado que da certeza, apoyo, seguridad. Generando vínculo.

[...] no, no, no, vamos a intentar consensuar, y esa incertidumbre que tú tienes... yo te apoyo. Porque si no, claro, me dejan a mí un marrón, que yo se lo paso a ella, entonces mejor consensuando en el equipo, y no es eximir las responsabilidades, que a veces se escucha eso, pero que nos digan en esta planta se va a hacer esto, en esta lo otro, pero consensuado con nosotros.
Durante el periodo de alarma ha sido muy difícil contar con estos espacios; la urgencia focalizada en el hacer, el miedo al contagio, la falta de medios en un inicio, nada de esto estaba contemplado en los protocolos. Sin embargo, se demandan como necesarios.

Habría que valorar qué tiempo dedicar al equipo [...]. Igual eso es lo que hace falta.

Se ponen en valor los espacios de aprendizaje que se han ido formado con anterioridad a la pandemia, y se los echa en falta.

[...] y estoy encantada con el equipo promotor que ha montado la directora del centro, el del Elder, estoy encantada, nos hemos abierto un montón, antes estábamos pensando, pero era tabú decirlo, no se podía hablar del tema, cómo puedo trasmitirlo, cómo puedo mejorarlo, hemos mejorado nuestra manera de comunicarnos. Hemos puesto en práctica cosas muy importantes, hemos puesto encima de la mesa valores muy importantes, el respeto, ponerte en lugar del otro, pensar antes de hablar, no cotillear [...], conocernos y aprender a decirnos las cosas, compartir temas de la unidad, cómo hacer, problemas, dificultades, cómo dar lo mejor de nosotros mismos a los residentes. He aprendido a empatizar conscientemente, aceptar los malos días, míos y de los demás, a pedir ayuda.

Se ve la necesidad de ampliar a más personas estos espacios de aprendizaje.

[...] somos veinticinco en este grupo de aprendizaje, el Elder. ¿Sabes lo que es? Y más de cien en el centro. Las que estamos en este círculo estamos poniéndolo en práctica, es muy directo practicarlo, se aprende poniéndolo en práctica, pero necesitamos más personas en esto para que se quede.

Nos ayudan a encauzarnos, nos dan herramientas, estamos muy contentos, te sientes reconocida, te sientes bien, el hecho de trasmitírselo a los compañeros también te reconforta, poder enseñarlo y que el compañero también lo ponga en práctica y le funcione, pues qué bien, entre todos vamos haciendo cositas enriquecedoras que nos hacen estar mejor con los usuarios.

Cuánto me he acordado de los espacios para pensar, lo he tenido muy presente.

Va apareciendo con fuerza la necesidad de "espacios para [...] volver a ser un todo". Para ello es necesario entrenar una capacidad muy poco reconocida aún en las organizaciones y muy necesaria para apoyar una filosofía de cuidados centrados en la persona, la capacidad para acoger la diversidad, para crear y sostener espacios conversacionales en los que la diferencia se expresa completamente, y se valora como un elemento fundamental para alcanzar la sabiduría colectiva. Esta capacidad es especialmente 
relevante cuando la diferencia viene revestida de tensión y conflicto. A su vez, en estos espacios se desarrolla el aprendizaje profesional, pensando entre todos la acción para ser transformada y ofreciendo así un descanso a los profesionales del cuidado.

A nivel individual, es una capacidad imprescindible para un liderazgo facilitador, consciente y transformador. A nivel organizacional, implica la creación y sostén de espacios seguros en los que las personas puedan expresarse en todo lo que son y con plenitud.

\section{Discusión}

Un virus desconocido, con una alta letalidad en personas mayores y con una rápida propagación en centros residenciales, llevó a las autoridades públicas a extremar las medidas de control para reducir factores de riesgo de enfermar y morir por esta causa (McMichael, 2020). Algunas de estas medidas fueron la cuarentena, el aislamiento y el distanciamiento social (Nussbaumer-Streit et al., 2020), así como el uso de equipos de protección individual (Verbeek et al., 2020; Chu et al., 2020). Todas estas medidas, que han demostrado su efectividad durante la propagación del virus, se aplicaron con especial intensidad en los centros residenciales, sin tener en cuenta sus potenciales efectos negativos sobre la salud y el bienestar de las personas mayores y de las profesionales que prestan cuidados. En este sentido, es esencial hacer una revisión ética y detallada de los procesos de atención, para que todas las personas que desempeñan su actividad en los centros residenciales tengan un marco de reflexión que las oriente en las decisiones sobre su práctica profesional (Leboni et al., 2020).

Este trabajo pretende hacer una contribución en el contexto residencial, en el que apenas se dispone de evidencias sobre los efectos de la pandemia en profesionales que proveen cuidados (Hussein, 2020). En concreto, se presenta y analiza la experiencia vivida por profesionales de centros residenciales de personas mayores en los meses iniciales de la pandemia de la covid-19. La información obtenida ha de ser interpretada en el marco de una organización que aplica la perspectiva de la atención centrada en la persona.

En primer lugar, la presencia constante de familias y residentes en los discursos de las profesionales muestra el carácter global y holístico de los cuidados, así como de las repercusiones de las medidas de control aplicadas en relación con la pandemia (aislamiento de personas, restricción de acompañamiento de las familias, etc.). Por ejemplo, medidas como la restricción de vistas de familias afecta no solo a las personas residentes y sus allegados, sino también al resto del entorno de cuidados del que las familias forman parte y que configuran con su presencia y atenciones. Del mismo modo, el miedo o la sobrecarga emocional experimentada por las profesionales afecta al bienestar de las personas residentes. Recíprocamente, cabe pensar que generar bienestar en las personas que se cuida solo es posible si este se experimenta por parte de las profesionales que cuidan.

Los discursos analizados muestran un impacto inicial caracterizado por una intensa carga emocional, miedo y una posterior y progresiva adaptación al cambio. A este proceso ha ayudado el trabajo en equipo en el marco de las unidades de convivencia como lugares donde ocurre la vida, ecosistemas vivos en los que personas usuarias, familiares, voluntarias y profesionales de referencia comparten los cuidados y cuidan del cuidado. El sentido de pertenencia, un propósito compartido y una actitud positiva y de confianza personal y en los demás han sido asimismo aspectos considerados importantes para el proceso de adaptación.

Se hace evidente en los discursos, por otro lado, la ruptura de los distintos vínculos que generan bienestar y hacen posible una atención personalizada (Prieto, 2014). Las personas entrevistadas apuntan algunas de las claves para restaurar esta esfera relacional. Señalan, en este sentido, la información, la comunicación, el reconocimiento y los espacios para el encuentro donde pensar juntas para trasformar la acción, gestionar las emociones y comprenderlas. Estrategias que contribuyen a restaurar o mantener una estructura relacional que promueva el bienestar de las profesionales $y$, por ende, una atención personalizada.

Concretamente, capacitar en prácticas para el autocuidado, entrenar en resiliencia y establecer espacios para la gestión emocional y la reflexión sobre los valores organizacionales no solo pueden ayudar a afrontar las situaciones de emergencia sanitaria como la que estamos viviendo, sino que además son esenciales en los contextos habituales de cuidados (Kunzler et al., 2020). Tomar conciencia de dónde se encuentra cada profesional consigo misma y en relación con los demás; abandonar actitudes de queja, de impotencia y de autojustificación en favor de la autorresponsabilidad y la prevención del cansancio constituyen competencias imprescindibles para el bienestar emocional y relacional de cuidadores profesionales.

En definitiva, la entrada de la covid-19 en las residencias conlleva efectos para la salud y bienestar de personas mayores, familiares y profesionales (Hussein, 2020). Las consecuencias de las medidas de control del virus suponen retos complejos para profesionales que están comprometidas en prestar cuidados ajustados a las preferencias y necesidades de las personas que los necesitan. En este trabajo, se han identificado recursos y estrategias que no solo pueden ser de utilidad en una situación de alerta sanitaria, sino que además pueden ser considerados para ser implantados en organizaciones comprometidas con el buen cuidado. 


\section{Conclusiones}

El análisis del discurso de las personas entrevistadas ha contribuido a comprender cómo un cambio brusco, que pone en juego la supervivencia, afecta a todas las personas que configuran el sistema de cuidados en los centros residenciales, poniendo en el centro a las personas. A las profesionales les ha exigido afrontar la carga emocional provocada por el miedo a lo desconocido, la pérdida de percepción de control y autonomía, la tensión del conflicto interno derivado de la fricción entre la atención deseada y la impuesta, así como la pérdida de rutinas.

Contactar con el sentido y el propósito del cuidado se revela como un punto de anclaje y de autoestima. Es necesario responder internamente y en colectivo al "para qué" de la organización. Ligado al propósito, aparecen en el discurso de las personas entrevistadas los valores culturales de la organización: actitud positiva, confianza, capacidad de adaptación, reconocimiento, colaboración y comunicación, a su vez, como fuentes de bienestar.

Surge también el equipo como lugar de encuentro donde aprender juntos, apoyarse y encontrar certezas y cuidados. Esto es posible en unidades pequeñas, con profesionales estables, que permiten la participación y la cooperación, dando paso a que la diversidad se exprese libremente.

El flujo de información se hace necesario para mantener el sistema vivo que es una organización de cuidados, tratando los bloqueos en la comunicación y las pérdidas de energía motivacional. Para entrenar y desarrollar estas capacidades se requieren espacios de encuentro y capacitación que, si bien se evidencian necesarios en situaciones de crisis como la actual, deberían ser considerados como acciones estables en organizaciones que apuestan por cuidados centrados en las personas. 
ARMITAGE, R. y NELLUMS, L.B. (2020): "COVID-19 and the consequences of isolating the elderly", The Lancet Public Health, vol. 5, $\mathrm{n}^{0} 5$, e256, <https://doi.org/10.1016/S24682667(20)30061-X>.

BEDFORD, J.; ENRIA, D.; GIESECKE, J.; HEYMANN, D.L.; IHEKWEAZU, C.; KOBINGER, G. et al. (2020): "Covid-19: towards controlling of a pandemic", The Lancet, no 395, pp. 1.015-1.017. 〈https://doi. org/10.1016/S0140-6736(20)30673-5>.

CHU, D.; AKL, E.; DUDA, S.; SOLO, K.; YAACOUB, S. y SCHÜNEMANN, H. (2020): "Physical distancing, face masks, and eye protection to prevent person-to-person transmission of SARSCoV-2 and COVID-19: a systematic review and meta-analysis", The Lancet, 〈https://doi. org/10.1016/S01406736(20)31142-9>.

DEUSDAD, B. (2020): “COVID-19 and Nursing Homes' crisis in Spain: Ageism and Scarcity of Resources", RASP - Research on Ageing and Social Policy, vol. 8, no 2, pp. 142-168, «https://doi. org/10.447/rasp.2020.5598>, 〈https://www. hipatiapress.com/hpjournals/index.php/rasp/ article/viewFile/5598/3092).

HOUGHTON, C.; MESKELL, P.; DELANEY, H.; SMALLE, M.; GLENTON, C.; STAND, A.; CHAN, X.H.; DEVANE, D. y BIESTY, L.M. (2020): "Barreras y facilitadores para la adherencia de los trabajadores de la salud con las recomendaciones de Prevención y Control de Infecciones para enfermedades infecciosas respiratorias: una síntesis de evidencia cualitativa", Base de Datos Cochrane de Revisiones Sistemáticas, 〈https://www.cochranelibrary.com/cdsr/ doi/10.1002/14651858.CD013582/full>.

HUSSEIN, S. (2020): “Report: Impact of COVID-19 on Frontline Long Term Care Workers' Wellbeing”,
LTCcovid.org, International Long-Term Care Policy Network, CPEC-LSE, «https://ltccovid. org/2020/03/31/report-impact-of-covid19-onfrontline-long-term-care-workers-wellbeing/>.

KUNZLER, A.M.; HELMREICH, I.; CHMITORZ, A.; KÖNIG, J.; BINDER, H.; WESSA, M. y LIEB, K. (2020): "Psychological interventions to foster resilience in healthcare professionals", Cochrane Database of Systematic Reviews, vol. 7, nCD012527, <https://doi.org/10.1002/14651858. CD012527.pub2〉.

LEBONI, A.; GRIGOROVICH, A.; BARNED, C.; RODRIGUES, K.; KONTOS, P.; CHU, C.; ASTELL, A. (2020): "Ethical guidance for people who work in longterm care: What is the right thing to do in a pandemic?", Dementia Isolation Toolkit Project, UHN Toronto Rehabilitation Institute, <https:// brainxchange.ca/Public/Files/COVID-19/ Ethical-Guidance-for-LTC-v1-4-23-20.aspx>.

LUPIÁNEZ-VILLANUEVA, F.; THERBEN, A.; ABADIE, F. y COAGNONE, C. (2015): Strategic Intelligence Monitor on Personal Health Systems Phase 3 (SIMPHS3). ETXEAN ONDO (Spain), Case Study Report, 〈http://dx.doi.org/10.2791/180635〉.

MCMICHAEL, T.M. (2020): “Epidemiology of Covid-19 in a Long-Term Care Facility in King County, Washington", The New England Journal of Medicine, 〈https://dx.doi. org/10.1056\%2FNEJMoa2005412〉.

McCORMARCK, B. y McCANCE, T. (2017): Person-Centred in Nursing and Health Care: Theory and Practice, Wiley Blackwell, Oxford.

NUSSBAUMER-STREIT, B.; MAYR, V.; DOBRESCU, A.; CHAPMAN, A.; PERSAD, E.; KLERINGS, I.; WAGNER, G.; SIEBERT, U.; CHRISTOF, C.; ZACHARIAH, C. y GARTLEHNER, G. (2020): 
"Quarantine alone or in combination with other public health measures to control COVID-19: a rapid review", Cochrane Database of Systematic Reviews, vol. 4, n- CD013574, 〈https://doi. org/10.1002/14651858.CD013574'.

PRIETO, D. (2014): La experiencia de los profesionales en el Modelo de Atención Centrado en la Persona, Matia Instituto, Donostia.

ROQUÉ, M. y COLL-PLANAS, L. (2020): ¿Cuáles son los efectos colaterales del confinamiento para evitar la COVID-19 en las personas mayores y las medidas para prevenirlos o tratarlos?, Cochrane Library, https://es.cochrane.org/ es $/ \% \mathrm{C}_{2} \% \mathrm{BFcu} \% \mathrm{C}_{3} \%$ A1les-son-los-efectoscolaterales-del-confinamiento-para-evitar-lacovid-19-en-las-personas
STACEY, G. (2020): “The place of person-centered care in an international response to the Covid-19 pandemic", International Practice Development Journal, vol. 10, nํㅜ 1, p. 1, «https://doi. org/10.19043/ipdj.101.001>.

VERBEEK, J.H.; RAJAMAKI, B.; IJAZ, S.; SAUNI, R.; TOOMEY, E.; BLACKWOOD, B.; TIKKA, C.; RUOTSALAINEN, J.H. y KILINC-BALCI, F.S. (2020): "Personal protective equipment for preventing highly infectious diseases due to exposure to contaminated body fluids in healthcare staff", Cochrane Database of Systematic Reviews, vol. 4, no CD011621, 〈https://doi. org/10.1002/14651858.CD011621.pub4). 